Check for updates

Cite this: Chem. Sci., 2019, 10, 3994

๑ All publication charges for this article have been paid for by the Royal Society of Chemistry

Received 21st December 2018 Accepted 26th February 2019

DOI: $10.1039 / \mathrm{c} 8 \mathrm{sc} 05735 d$

rsc.li/chemical-science

\section{Controlling nanoemulsion surface chemistry with poly(2-oxazoline) amphiphiles $\uparrow$}

\author{
Daniel A. Estabrook, (D) Amanda F. Ennis, + Rachael A. Day and Ellen M. Sletten (iD *
}

Emulsions are dynamic materials that have been extensively employed within pharmaceutical, food and cosmetic industries. However, their use beyond conventional applications has been hindered by difficulties in surface functionalization, and an inability to selectively control physicochemical properties. Here, we employ custom poly(2-oxazoline) block copolymers to overcome these limitations. We demonstrate that poly(2-oxazoline) copolymers can effectively stabilize nanoscale droplets of hydrocarbon and perfluorocarbon in water. The controlled living polymerization of poly(2-oxazoline)s allows for the incorporation of chemical handles into the surfactants such that covalent modification of the emulsion surface can be performed. Through post-emulsion modification of these new surfactants, we are able to access nanoemulsions with modified surface chemistries, yet consistent sizes. By decoupling size and surface charge, we explore structure-activity relationships involving the cellular uptake of nanoemulsions in both macrophage and non-macrophage cell lines. We conclude that the cellular uptake and cytotoxicity of poly(2-oxazoline)-stabilized droplets can be systematically tuned via chemical modification of emulsion surfaces.

\section{Introduction}

Facile methods to reliably prepare complex materials facilitate new technologies and medicines. Towards the development of optoelectronic materials and sensors, predictable assemblies of hard nanomaterials have enabled emergent optical, electronic, and magnetic properties. ${ }^{\mathbf{1 - 4}}$ For biomedical applications, the advantageous safety and clearance properties of soft organic materials have propelled liposomes, polymer micelles, hydrogels, and dendrimers into the research spotlight. ${ }^{5-10}$ Surprisingly, far less attention has been placed on incorporating chemical complexity into emulsions ${ }^{\mathbf{1 1 - 1 3}}$ despite their simple formation and ability to encapsulate significant amounts of cargo. $^{14-16}$

Emulsions are liquid-in-liquid droplets stabilized by surfactant, with size distributions ranging from several nanometers to hundreds of micrometers. ${ }^{17}$ These materials have traditionally been employed as delivery systems ${ }^{18,19}$ in cosmetic, ${ }^{20}$ food, ${ }^{21,22}$ and pharmaceutical industries, ${ }^{23-25}$ with more advanced applications including templates for material synthesis ${ }^{26-30}$ and nanoscale reactors. ${ }^{31-34}$ While these emerging applications showcase the potential versatility of emulsions, liquid droplets

Department of Chemistry and Biochemistry, University of California, 607 Charles E. Young, Dr. E., Los Angeles, CA 90095, USA. E-mail: sletten@chem.ucla.edu

$\dagger$ Electronic supplementary information (ESI) available: Fig. S1-S37, Table S1, supporting equations, detailed experimental procedures, characterization of 3-11, 14-17. See DOI: 10.1039/c8sc05735d

\$ Present address: Department of Chemistry, Duke University, 124 Science Drive, Durham, NC 27708, USA. remain underdeveloped compared to other soft materials. ${ }^{\mathbf{1 1 , 1 2 , 3 5}}$ Currently, a challenge in the preparation of emulsions is decoupling the size and surface charge of the materials. ${ }^{36,37}$ Furthermore, chemically robust approaches to append functionality to the surface of emulsions are limited in comparison to conventional nanoparticles..$^{12,13,35,38,39}$ Surfactants play
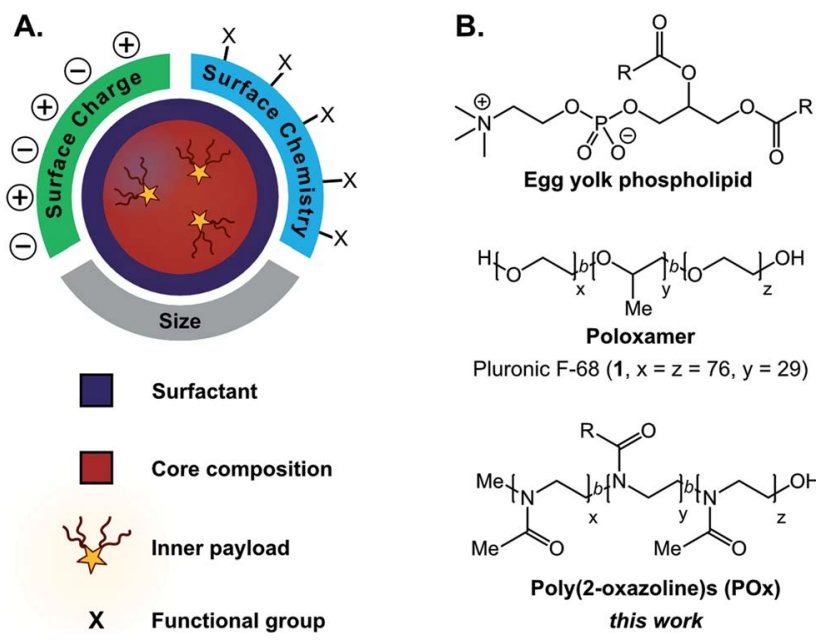

Fig. 1 (A) Surfactants dictate the size, charge, and surface chemistry of emulsions. Emulsion cores can be composed of several liquid phases (e.g. oil, perfluorocarbon). Payloads can be solubilized in the emulsion core and functional groups can be appended on the surface. (B) Selected surfactants for emulsion formation, including poly(2-oxazoline) surfactants presented herein. 
a critical role in the formation and stabilization of emulsions, directly affecting the size, surface charge, and stability of the droplets (Fig. 1A)..40,41 This class of amphiphilic molecules can be composed of small molecules or polymers. They orient at the liquid-liquid interface to reduce interfacial tension between the immiscible emulsion core and bulk phases. Simple surfactants such as phospholipids and poloxamers (Fig. 1B) are routinely used for industrial applications, while recently engineered peptide, ${ }^{42-44}$ polymer, ${ }^{45}$ and nanoparticle ${ }^{46}$ surfactants have produced responsive materials ${ }^{47,48}$ and sophisticated architectures. Slight changes in surfactant structure can drastically affect the physiochemical properties of the emulsions. ${ }^{39}$ These subtleties make the systematic alteration of a single characteristic difficult, precluding structure-property relationships. A method that will facilitate the decoupling of size and surface charge is the ability to control surface chemistry after the droplet has been formed.

The role of the surfactant in stabilizing droplets has largely precluded the ability to engineer emulsion surfaces, particularly for nanoemulsions, whose interface composition is dictated by the need to impart kinetic stability. Conventional emulsion surface functionalization techniques involve modification of the surfactant prior to emulsification. ${ }^{13,49-51}$ The functionalized surfactant can be employed solely or in combination with other surfactants. Limitations to this approach are the reliance on cosurfactants ${ }^{52}$ and the inability to decouple size and surface charge. An alternative approach is the introduction of a functionalized amphiphile after emulsification that can absorb on the surface. ${ }^{49}$ This competitive absorption mechanism allows for surface chemistry alteration, ${ }^{53}$ but risks desorption of the modified surfactant. ${ }^{35}$ Other post-emulsification strategies rely on reversible chemical interactions with the surfactant at the liquid-liquid interface. Reported approaches involve electrostatic deposition, ${ }^{54-56}$ designer peptide amphiphiles, ${ }^{42,57,58}$ or reactive copolymer surfactants for disulfide exchange..$^{59}$ These techniques are all environment-dependent, limiting their generalizability. Irreversible covalent modification of macroemulsion surfaces have previously been enabled by end-group functionalization of commercially available surfactants..$^{60,61}$ Notably, these approaches suffer from low occupancy of functional groups on the droplet surface and did not allow access to droplet sizes relevant for biomedical applications $(<200 \mathrm{~nm}) .^{62}$ Comparatively, nanoemulsion interfaces have much higher surface areas and provide a more challenging interface to both stabilize and functionalize, as exemplified by previous low-yield attempts reliant on cosurfactants. ${ }^{59}$ To enable robust, covalent modification of nanoemulsions, we devised a versatile, topdown approach involving custom surfactants with chemical handles that undergo covalent modification at the liquid-liquid interface.

When considering the design of surfactants that will enable post-emulsion modification, we looked to amphiphilic copolymers. Polymer surfactants benefit from steric stabilization and tunable properties via alterations in block structure. ${ }^{63,64} \mathrm{We}$ hypothesized that chemical handles could be incorporated into the hydrophilic block without destabilizing the droplets. A popular class of polymer surfactants are poloxamers: block copolymers of poly(ethylene oxide) and poly(propylene oxide) (Fig. 1B). While poloxamers (e.g. Pluronic F-68, 1) have been extensively validated as surfactants for emulsions, it is synthetically challenging to incorporate chemical functionality into them. Additionally, poly(ethylene oxide)-containing amphiphiles, like many surfactants employed for pharmaceutical emulsion formulations, ${ }^{65-67}$ are associated with immunogenicity, making them a poor choice for materials with biomedical applications. ${ }^{68,69}$ Recent work has suggested that poly(2-methyl-2-oxazoline) has similar protein repellent features to poly(ethylene oxide). ${ }^{70-72}$ Poly(2-oxazoline)s (POx) are synthesized through a controlled, living polymerization, facilitating tunable block structure, length, and selective comonomer addition..$^{73,74}$ Based on these collective attributes, we focused on amphiphilic poly(2-oxazoline) surfactants to decouple the physiochemical properties of nanoemulsions and facilely control their surface chemistry.

Herein, we report a panel of POx surfactants for the stabilization and functionalization of nanoemulsions, kinetically stabilized emulsions less than $500 \mathrm{~nm}$ in size. ${ }^{75}$ We showcase the controlled living polymerization of POx to incorporate comonomers into the hydrophilic block of the surfactants to facilitate post-emulsion functionalization. We find that thiolene and copper-catalyzed azide-alkyne cycloaddition (CuAAC) chemistries are successful at the liquid-liquid interface, overcoming a key obstacle in emulsion functionalization. ${ }^{11,12} \mathrm{We}$ demonstrate that these chemistries can decouple emulsion properties by altering the charge of similarly-sized droplets.

A scenario where both the size and charge of particles directly influence function is cellular uptake. Controlling cellnanoparticle interactions is essential for advancements in nanomedicine. Previous work has explored the relationship between size, charge, and cellular uptake by modulating the surface chemistry of gold nanoparticles, ${ }^{76-78}$ micelles, ${ }^{79}$ and peptide-brush polymers. ${ }^{80}$ These studies indicate that not only is the surface chemistry important but also the nanomaterial composition. The custom surfactants reported herein allowed us to extend the scope of cellular uptake studies to include nanoemulsions. Through decoupling of size and surface charge, we find that macrophage and non-macrophage cells display charge-dependent cellular uptake.

\section{Results and discussion}

We first synthesized a small library of amphiphilic diblock and triblock poly(2-oxazoline) amphiphiles and explored their ability to stabilize oil-in-water and perfluorocarbon-in-water nanoemulsions (Fig. 2). The polymer surfactants were designed to mimic Pluronic F-68 (1), with poly(2-methyl-2oxazoline) replacing poly(ethylene oxide) and either poly(2propyl-2-oxazoline), poly(2-nonyl-2-oxazoline), or poly(2-(perfluorohexyl)ethyl-2-oxazoline) ${ }^{81-83}$ replacing the hydrophobic poly(propylene oxide). The POx surfactants were synthesized through a controlled, living cationic ring-opening polymerization of corresponding 2-substituted-2-oxazoline monomers (Fig. 2A, 2-5). Due to the controlled nature of the polymerization mechanism, block lengths were tuned by initiator to 
A.
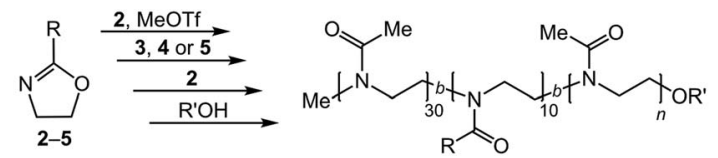

$\mathrm{R}^{\prime}=\mathrm{H}, \mathrm{COCH}=\mathrm{CH}_{2}$

2, $\mathrm{R}=\mathrm{CH}_{3}$

$3, \mathrm{R}=\mathrm{C}_{3} \mathrm{H}_{7}$

$4, \mathrm{R}=\mathrm{C}_{9} \mathrm{H}_{19}$

$\mathbf{5}, \mathrm{R}=\mathrm{C}_{2} \mathrm{H}_{4} \mathrm{C}_{6} \mathrm{~F}_{13}$
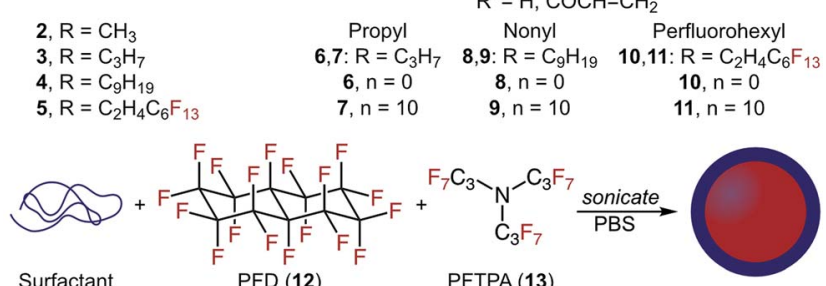

Surfactant
$(1,6-11)$

B.

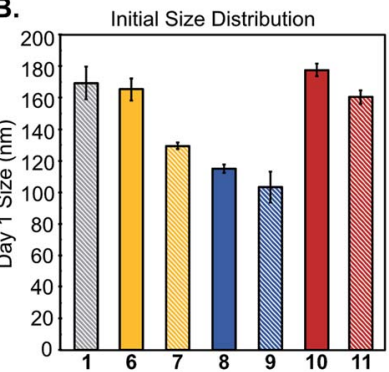

C.

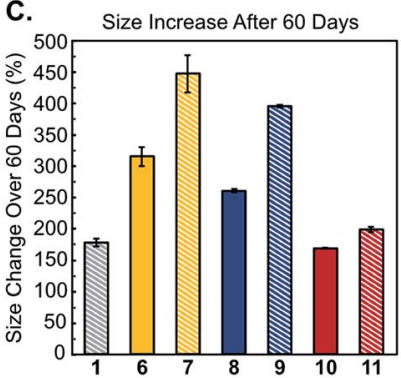

Fig. 2 (A) Library of amphiphilic di- and triblock copolymers 6-11 and $(B / C)$ their utility as surfactants for PFC nanoemulsions composed of $7: 3 \mathrm{v} / \mathrm{v} \%$ perfluorodecalin (PFD, 12) : perfluorotripropylamine (PFTPA, 13). (B) Initial size distributions of POx-stabilized emulsions. Emulsions were prepared by sonicating a solution of 2.8 wt\% surfactant with 10 vol\% $7: 3$ PFD : PFTPA in phosphate buffered saline (PBS). Emulsions were diluted $1: 100$ in MilliQ water prior to measurements by dynamic light scattering (DLS). Data represents the average of three independent samples; error bars represent the half-width at halfmaximum averaged over the three independent samples. (C) Ostwald ripening of emulsions over 60 days monitored by LS, see Fig. S7-S9† for raw data. Error bars represent the standard deviation of percent size changes for three independent samples.

monomer ratio. ${ }^{74}$ Hydrophilic blocks were kept at 30 repeat units of 2-methyl-2-oxazoline (2), while hydrophobic blocks (composed of 3,4 or 5) were kept at 10 repeat units. Block lengths were chosen at a ratio analogous to $\mathbf{1}$, with shorter lengths to speed surfactant migration to the interface. ${ }^{64}$ Microwave-assisted polymerization allowed for short reaction times and low dispersities (Table 1) compared to traditional solution phase synthesis. ${ }^{84}$ Polymerizations were quenched with acrylic acid to aid determination of number average molecular weight $\left(M_{\mathrm{n}}\right)$ via end-group analysis. Following this procedure, we prepared polymers 6-11 (Fig. 2A, Table 1) and characterized them to have $M_{\mathrm{n}}$ from 3.5 to $8.9 \mathrm{kDa}$ with narrow dispersities $(\theta \leq 1.30)$.

Next, we evaluated the ability of poly(2-oxazoline)s 6-11 to act as surfactants for nanoemulsions. Poly(2-oxazoline)s have been thoroughly investigated for micellization ${ }^{82,83,85}$ and have previously been employed for chloroform-in-water macroemulsions, ${ }^{86}$ yet their use as surfactants for nanoemulsion formation is novel. ${ }^{89}$ Our main interest lies in perfluorocarbonin-water nanoemulsions, ${ }^{90-93}$ as the orthogonality of the fluorous phase provides opportunities to selectively sequester fluorous-tagged payloads inside the droplets. ${ }^{94}$ Historically,

Table 1 Surfactant library of amphiphilic poly(2-oxazoline)s.

\begin{tabular}{llll}
\hline Polymer $^{a}$ & $M_{\mathrm{n}}{ }^{b}(\mathrm{kDa})$ & $D^{c}$ & \\
\hline $\mathbf{6}$ & $\mathrm{P}\left(\mathrm{MeOx}_{30}-b-\mathrm{PrOx}_{7}\right)$ & 3.5 & 1.26 \\
7 & $\mathrm{P}\left(\mathrm{MeOx}_{30}-b-\mathrm{PrOx}_{7}-b-\mathrm{MeOx}_{30}\right)$ & 6.2 & 1.29 \\
$\mathbf{8}$ & $\mathrm{P}\left(\mathrm{MeOx}_{30}-b-\mathrm{NonO}_{12}\right)$ & 4.8 & 1.24 \\
$\mathbf{9}$ & $\mathrm{P}\left(\mathrm{MeOx}_{30}-b-\mathrm{NonOx}_{10}-b-\mathrm{MeOx}_{30}\right)$ & 7.4 & 1.29 \\
$\mathbf{1 0}$ & $\mathrm{P}\left(\mathrm{MeOx}_{29}-b-\mathrm{FOx}_{9}\right)$ & 6.6 & 1.16 \\
$\mathbf{1 1}$ & $\mathrm{P}\left(\mathrm{MeOx}_{29}-b-\mathrm{FOx}_{9}-b-\mathrm{MeOx}_{29}\right)$ & 8.9 & 1.09
\end{tabular}

${ }^{a}$ MeOx: methyl-2-oxazoline, 2; PrOx: propyl-2-oxazoline, 3; NonOx: nonyl-2-oxazoline, 4; FOx: (perfluorohexyl)ethyl-2-oxazoline, $\mathbf{5}$. ${ }^{b}$ Number-average molecular weight $\left(M_{\mathrm{n}}\right)$ determined by ${ }^{1} \mathrm{H}-\mathrm{NMR}$ endgroup analysis of terminal $\mathrm{CH}_{3}$ group to polymeric backbone. Acrylic acid termination was found to be quantitative for polymers 6-9 (ESI, p. S57-S60), while 10 and 11 (ESI, p. S61-S62) were hydroxylterminated due to extended reaction times. The extended reaction times may also lead to chain transfer and chain coupling side reactions..$^{87,88}{ }^{c}$ Dispersity index $(D)$ determined by SEC analysis (eluent: DMF + 0.1 M LiBr).

perfluorocarbon (PFC) nanoemulsions have been stabilized by Pluronic F-68 (1) for use as artificial blood substitutes; ${ }^{95}$ however, these surfactants have been associated with formulation inconsistencies and multidose toxicity. ${ }^{96-98}$ Contemporary applications of PFC nanoemulsions such as ${ }^{19} \mathrm{~F}$-magnetic resonance imaging, ${ }^{51,99,100}$ ultrasound contrast agents, ${ }^{45,101}$ photodynamic therapy, ${ }^{92,102}$ and intracellular sensors ${ }^{103}$ have spawned interest in new formulations. We previously looked to commercially available polymers and biomolecules for the stabilization and surface functionalization of PFC emulsions, but found these materials unsuitable due to large size and rapid degradation of the droplets, as well as limitations in postemulsion functionalization. ${ }^{90}$ Recently, volatile perfluorocarbon droplets have been effectively stabilized by Gianneschi and coworkers through triblock poly(norbornene)s, ${ }^{45}$ and by Medina et al. through crosslinked peptides. ${ }^{44}$ However, neither of these efforts explored surface modification. Taken together, these works suggest interest and need for custom polymer surfactants that facilitate functionalizable, stable PFC nanoemulsions.

To test the ability for POx amphiphiles to stabilize nanoemulsions, polymers 6-11 were first solubilized in dimethylformamide and then diluted with phosphate buffered saline (PBS, pH 7.4) to a final surfactant loading of $2.8 \mathrm{wt} \%$. This solution was combined with 10 vol\% fluorous or hydrocarbon oil. Emulsions were formulated through ultrasonication for 15 minutes at $0{ }^{\circ} \mathrm{C}$. For the fluorous solvent, we selected a $7: 3(\mathrm{v} /$ $\mathrm{v} \%)$ mixture of perfluorodecalin : perfluorotripropylamine (PFD : PFTPA, $12: 13$ ) due to its use in Fluosol-DA, a previously FDA-approved PFC nanoemulsion stabilized by Pluronic F-68 (1).$^{95}$ Dynamic light scattering analysis of POx-stabilized PFC nanoemulsions showed size distributions that were comparable to or smaller than droplets stabilized by 1 (Fig. 2B), with polydispersities ranging from 0.1 to 0.2 (Fig. S1-S6 $\dagger$ ). Monitoring the size over 60 days at ambient temperature indicated that propyl-2-oxazoline-containing surfactants $(6,7)$ were inferior, exhibiting significant Ostwald ripening $(>300 \%$ change in size, Fig. 2C), despite structural analogy to 1 . The more hydrophobic 
nonyl-2-oxazoline-containing surfactants $(\mathbf{8}, \mathbf{9})$ were superior to the propyl-containing surfactants with diblock 8 performing better than triblock 9. Surfactants with fluorous components $(\mathbf{1 0}, \mathbf{1 1})$ displayed the best stability over time, on par with $\mathbf{1}$. Emulsions stabilized by triblock copolymers 7, 9, and $\mathbf{1 1}$ resulted in smaller initial size distributions, but increased in swelling over time compared to diblock copolymers 6, 8 and 10. When employed for olive oil emulsion formation, 6-9 resulted in sub-250 nm droplets (Fig. S10-S15†). As expected, the fluorous copolymers $\mathbf{1 0}$ and $\mathbf{1 1}$ were not effective surfactants for the formation of oil-in-water nanoemulsions. After 3 weeks, oil droplets stabilized by propyl-2-oxazoline-containing surfactants $(6,7)$ underwent phase separation. In contrast, emulsions stabilized by nonyl-2-oxazoline-containing surfactants $(\mathbf{8}, \mathbf{9})$ showed no size change (Fig. S15†). These data demonstrate that the following results on PFC nanoemulsions can be extended to more conventional oil-in-water nanoemulsions. Our initial library of poly(2-oxazoline) surfactants resulted in amphiphilic copolymers that performed similarly to 1 yet could be prepared through a controlled living polymerization. Diblock copolymers $\mathbf{8}$ and $\mathbf{1 0}$ stood out as the most promising, as $\mathbf{8}$ formed emulsions of small size for both oil-in-water and PFC nanoemulsions, while $\mathbf{1 0}$ formed PFC emulsions with good stability. Work toward expanding this library to elucidate the role of the surfactant's hydrophilic-lipophilic balance, block length and structure on emulsion size and stability are underway. Here, we focus on the creation of POx surfactants that allow for modification of the emulsion surface, such that size and surface charge can be decoupled.

Surfactants that could be further functionalized were synthesized by incorporating alkene and alkyne functionality into the hydrophilic poly(2-methyl-2-oxazoline) block of POx amphiphile 8. Alkene and alkyne functionalities were chosen due to their ability to undergo thiol-ene and CuAAC "click" chemistries, respectively. These classes of reactions benefit from their high efficiency, modularity, and water compatibility-all desirable characteristics for the proposed postemulsion modification route. ${ }^{104,105}$ To prepare functionalizable POx surfactants, we initiated the polymerization of $5: 30$ 2-(3butenyl)-2-oxazoline (14) or 2-(4-pentynyl)-2-oxazoline (15) to methyl-2-oxazoline (2,15 mol\% alkene/alkyne) with methyl triflate. Once all monomer was consumed, nonyl-2-oxazoline (4) was introduced to the reaction mixture to form the hydrophobic block (Fig. 3A). Previous work has demonstrated that $\mathbf{1 4}$ or $\mathbf{1 5}$ may be statistically incorporated into the poly(2-methyl-2oxazoline) chain. ${ }^{106,107}$ The resulting alkene- or alkynecontaining surfactants, $\mathbf{1 6}$ and $\mathbf{1 7}$ respectively, were characterized by NMR and SEC to contain the desired chemical handles and have $M_{\mathrm{n}}$ and dispersities comparable to surfactant 8 (Table S1†). With these polymers in hand, we first optimized conditions for thiol-ene and click chemistry based on literature precedent. ${ }^{106-108}$ Alkene-containing POx 16 underwent quantitative thiol-ene chemistry by treatment with mercaptoacetic acid (18, 5.0 equiv.), Irgacure D-2959 photoinitiator ( 0.2 equiv.), and irradiation with $365 \mathrm{~nm}$ light (output power: $3 \times 325 \mathrm{~mW}$ at $365 \mathrm{~nm}$ ) overnight to result in modified polymer 19 (Fig. 3B and D). Similarly, polymer $\mathbf{1 7}$ underwent complete conversion to
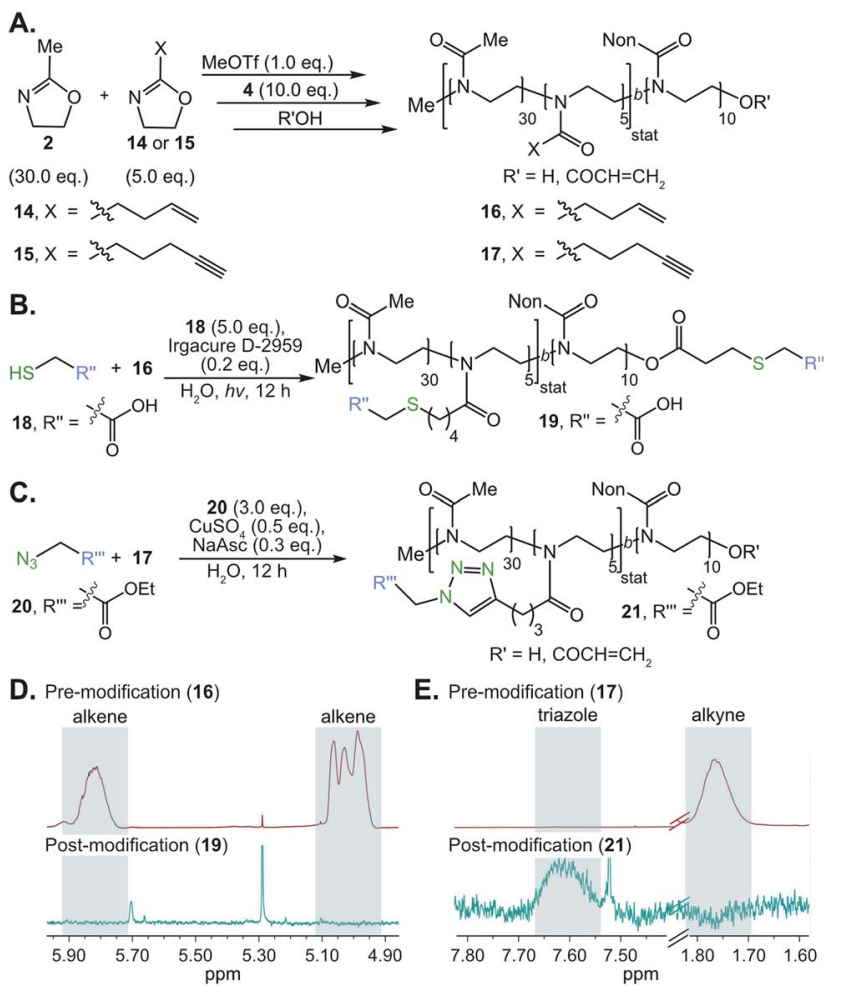

Fig. 3 (A) Synthesis of a functionalized POx surfactant. A functional comonomer is randomly incorporated within the hydrophilic block to yield alkene (16) or alkyne (17) functionalized surfactants. (B/C) Couplings with thiol- (B) or azide-modified (C) payloads allow for modification of copolymers (NaAsc $=$ sodium ascorbate). (D/E) ${ }^{1} \mathrm{H}$ NMR analysis indicates quantitative modification.

yield modified polymer 21 (Fig. 3C and E) upon treatment with ethylazidoacetate (20, 3.0 equiv.), cupric sulfate ( 0.5 equiv.) and sodium ascorbate ( 0.3 equiv.), stirring at room temperature overnight.

The optimized thiol-ene and click chemistries were then extended from a post-polymerization to a post-emulsification modification strategy. PFC nanoemulsions stabilized by $\mathbf{1 6}$ and $\mathbf{1 7}$ were prepared following the conditions employed for $\mathbf{8}$ (Fig. 4A). The resulting emulsions were found to be similar in size, polydispersity and long-term stability to 8 (Fig. 4A and B, S16 $\dagger$ ), indicating the presence of $15 \mathrm{~mol} \%$ comonomer did not significantly disrupt the hydrophilic-hydrophobic balance of the surfactant. At $15 \mathrm{~mol} \%$ incorporation of functional handles, these $\sim 120 \mathrm{~nm}$ emulsions contain an estimated 3600 functional groups displayed on the droplet surface-however, this value can be easily modulated through the comonomer feed ratio (see ESI $\uparrow$ for calculation details).

Nanoemulsions prepared from $\mathbf{1 7}$ that contained alkynes on the surface were fluorescently modified by treatment with azidorhodamine 22 (3.0 equiv.), cupric sulfate ( 0.5 equiv.) and sodium ascorbate ( 0.3 equiv.) (Fig. 4C). As a control, an emulsion stabilized by the corresponding non-functionalized surfactant (8) was exposed to identical conditions. Emulsion sizes were monitored before and after the reaction to confirm that the reagents did not disrupt nanoemulsion stability 
A.

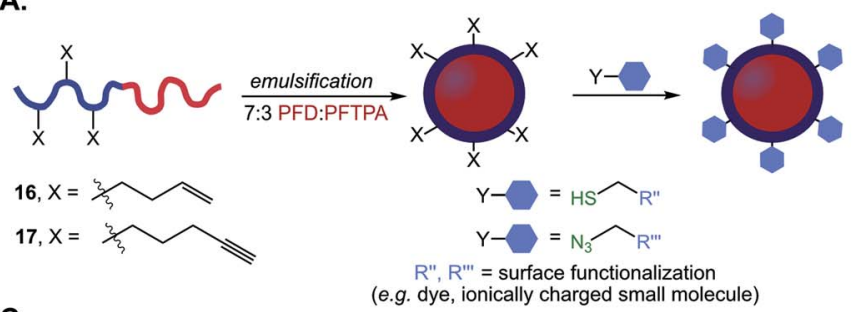

C.

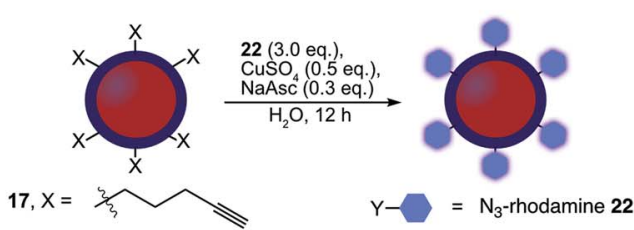

E.

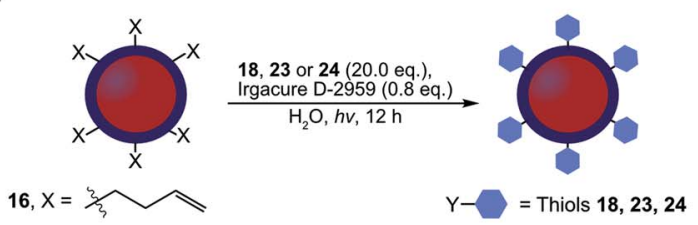

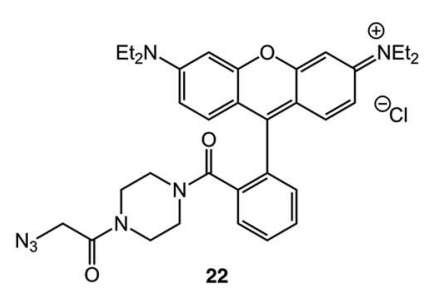

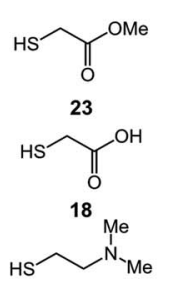

24

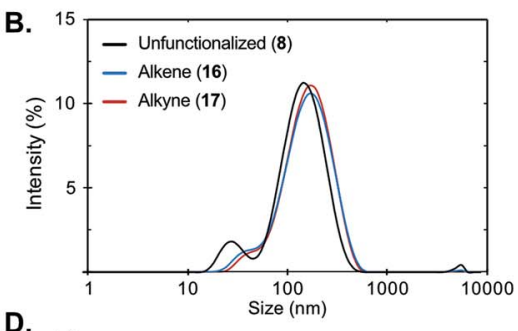

D.
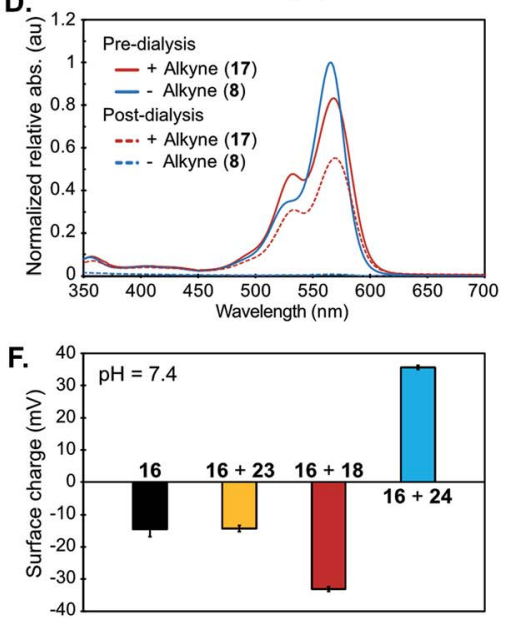

Fig. 4 (A) Schematic of post-emulsion modification strategy with surfactants 16 and 17. (B) Dynamic light scattering data of emulsions formed from 8, 16, 17. Emulsions were prepared with 10 vol\% $7: 3$ PFD/PFTPA and 2.8 wt\% surfactant in PBS, diluted $1: 100$ in MilliQ water and analyzed via DLS. (C) CuAAC chemistry is employed for emulsion surface functionalization with azidorhodamine dye 22 (NaAsC = sodium ascorbate). (D) Emulsions formed from 8 and 17 were subjected to the CuAAC chemistry conditions in (C). After $12 \mathrm{~h}$, the reaction mixtures were diluted $1: 100$ in MilliQ water and their absorbance was measured (pre-dialysis, solid lines; red $=17$, blue $=8$ ). The remaining solution was dialyzed in water for $24 \mathrm{~h}$ with 3 water changes, at which point the emulsion solution was removed and analyzed by UV/Vis at the approximate concentration as the previous measurements (post-dialysis, dotted lines; red $=17$, blue $=8$ ). All the data were normalized to emulsion 8 pre-dialysis. See Fig. S17 $\uparrow$ for size analysis before and after reaction and dialysis. (E) Thiol-ene chemistry allows for modulation of zeta potential with thiols methyl mercaptoacetate (23), mercaptoacetic acid (18), and 2-dimethylaminoethanethiol (24). (F) Zeta potential of the emulsions at pH 7.4 before (16) and after thiol-ene modification following the conditions in (E). Black=emulsions stabilized by 16; yellow =emulsions stabilized by 16 and modified by 23 ; red = emulsions stabilized by 16 and modified by 18 ; blue = emulsions stabilized by 16 and modified by 24 . The surface charge was analyzed by diluting the reaction mixtures $1: 100$ in MilliQ $\mathrm{H}_{2} \mathrm{O}$ and measuring the zeta potential. Data is representative of five replicate measurements. Error bars represent the standard deviation of five measurements. See Fig. S21† for raw zeta potential traces.

(Fig. S17 and S18†). The rhodamine absorption of the emulsion solutions exposed to CuAAC conditions was measured by UV-Vis spectroscopy before and after dialysis of the samples to confirm removal of non-conjugated dye. An increased shoulder on the emulsions with conjugated alkyne suggested aggregation of the fluorophores due to high local concentration on the surface of the droplets (Fig. 4D, red lines). Covalent modification of the surface of the droplets was confirmed after dialysis purification as the alkyne-containing emulsions retain absorption from the rhodamine while the control emulsions were no longer colored (Fig. 4D, dashed lines). Emission spectra as well as ${ }^{1} \mathrm{H}-\mathrm{NMR}$ of surfactant isolated post-reaction further confirmed quantitative consumption of the alkyne chemical handles (Fig. S19 and S20†).

Alongside verification that $\mathrm{Cu}$-catalyzed click chemistry was successful at the nanoemulsion surface using a rhodamine dye, we validated that the thiol-ene reaction was a viable approach for post-emulsion modification by modulating the surface charge of the droplets. Changes in surface charge could be quantified by zeta potential analysis, which did not require a purification step. PFC nanoemulsions stabilized by $\mathbf{1 6}$ were subjected to photoinitiator (0.8 equiv., Irgacure D-2959) in the presence of thiols (20.0 equiv.) methyl mercaptoacetate (23), mercaptoacetic acid (18), or 2-dimethylaminoethanethiol (24), which will have different protonation states at physiological $\mathrm{pH}$. These solutions were irradiated with $365 \mathrm{~nm}$ light overnight and the zeta potential of the samples were measured (Fig. $4 \mathrm{E} / \mathrm{F}$, S19 $\dagger$ ). As compared to control emulsions stabilized by unmodified 16 (black, Fig. 4F), treatment with thiols 23, 18 and 24 exhibit the expected changes in zeta potential: neutral 23 displays no significant change, acid 18 results in more negatively charged droplets, and amine $\mathbf{2 4}$ gives positively charged emulsions. Control reactions lacking reagents (thiol, light or photoinitiator) display little change in zeta potential (Fig. S22 $\dagger$ ). Note that at physiological pH (Fig. S27 $\dagger$ ), the zeta potential of emulsions stabilized by unmodified polymer $\mathbf{1 6}$ is negative, which is consistent with results found for poly(2-methyl-2oxazoline)s in solution. ${ }^{109}$ The thiol-ene chemistry was further confirmed by NMR analysis of isolated surfactant after the modified emulsions have been disassembled (Fig. S23-S26†). 
Using the thiol-ene post-emulsification strategy, we can modulate the zeta potential of the droplets from +35 to $-35 \mathrm{mV}$ at pH 7.4 while keeping the size constant (Fig. S28†). Notably, it is difficult to obtain emulsions with identical sizes but varied surface charges, as ionic surfactants stabilize interfacial tensions differently compared to non-ionic surfactants. ${ }^{37} \mathrm{We}$ demonstrated that the pre-emulsion functionalization of the surfactants yielded distinct nanoemulsions when compared to post-emulsion modification. Polymers were prepared by reacting 16 with thiols $\mathbf{1 8}, \mathbf{2 3}$, or $\mathbf{2 4}$. After isolation, these surfactants were subjected to standard PFC nanoemulsion formation conditions (Fig. 5A). We then compared the size and surface charge of emulsions resulting from the pre- or postemulsification approach to emulsions stabilized by unmodified surfactant 16 (Fig. 5B). As expected, there was no statistically significant difference in size for emulsions modified with neutral thiol 23 (Fig. 5B, yellow). In contrast, differences were observed in the size of anionic and cationic emulsions (Fig. 5B, red and blue, respectively). Overall, emulsions formed through a pre-emulsification method varied in size by up to $35 \mathrm{~nm}$, while post-emulsion modification resulted in nanoemulsions with only a $5 \mathrm{~nm}$ variance. These results showcase that postemulsion surface functionalization is a viable approach to decouple the zeta potential of nanoemulsions from their size.

With the ability to access this unique set of nanoemulsions, we performed a systematic study to identify how emulsion surface charge affects cellular uptake (Fig. 6A). It is known that the size, zeta potential, and surface chemistry of nanoparticles

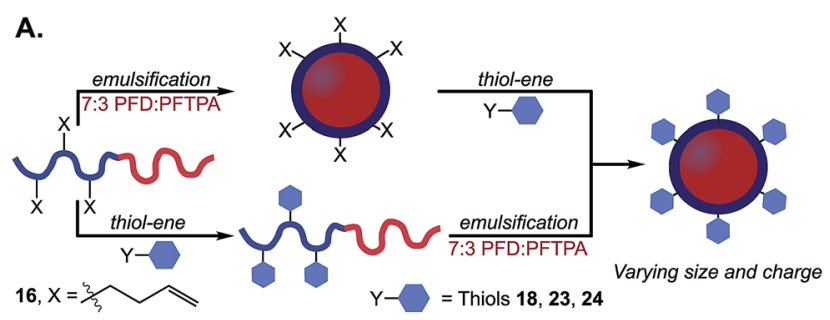

B.

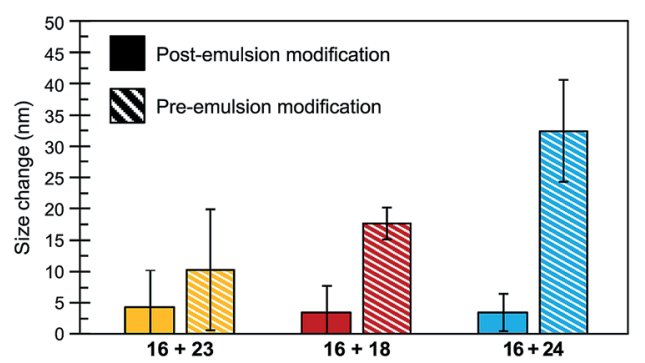

Fig. 5 (A) Schematic of emulsions modified through post- (top) or pre- (bottom) emulsion modification methods. (B) Thiol-ene chemistries were performed on surfactant 16 with thiols 18,23 or 24 either before (conditions in Fig. 3B) or after emulsification (conditions in Fig. 4E). The emulsions were diluted 1:100 in MilliQ water and analyzed by DLS. Plotted are the size changes as determined by the absolute difference between size distributions of the resulting emulsions and control emulsions formulated with unmodified 16 . Size data is representative of the average of three independent samples, with three replicate measurements; error bars represent the standard deviation of three independent samples. See Fig. S29† for emulsion size distributions and statistical significance. dictate cell uptake in vitro, ${ }^{\mathbf{7 8 , 1 1 0}}$ but these experiments have primarily been performed on hard nanomaterials (e.g. gold nanoparticles $\left.{ }^{\mathbf{7 8 , 1 1 1 , 1 1 2}}\right)$, micelles ${ }^{\mathbf{1 1 3 - 1 1 5}}$ or liposomes. ${ }^{\mathbf{1 0 , 1 1 6 , 1 1 7}}$ Results have shown that nanoparticle composition and cell type are also important factors in cell uptake, making studies on nanoemulsions an important addition to this field of study.

We assayed the cellular uptake of PFC nanoemulsions in both macrophage and non-macrophage cell lines by loading a fluorous-soluble rhodamine dye $(25 \text {, Fig. } 6 \mathrm{~B})^{\mathbf{9 1}}$ into the emulsion core. The resulting fluorescent nanoemulsions were incubated with A375 (human melanoma, non-macrophage) or RAW (macrophage) cell lines for 3 hours and, after washing, their degree of fluorescence was quantified by flow cytometry (Fig. 6C and D). We performed these studies on emulsions formed from 16 either unmodified or functionalized with 18, 23, or 24. We also employed emulsions stabilized with 1 as a control. These experiments showed that cationic nanoemulsions were uptaken in the A375 non-macrophage cell line $250 \%$ more than the neutral emulsions and $370 \%$ more than the anionic emulsions (Fig. 6C). This preference for cationic particles is consistent with other nanomaterial uptake studies. ${ }^{118-121}$ Notably, conjugation with neutral thiol 23 resulted in cellular uptake levels similar to that of unmodified 16, indicating that discrepancies in cellular uptake are due to differences in the physicochemical properties of the nanoemulsions, and not a result of the chemical modification process.

When the series of differentially charged nanoemulsions were incubated with the RAW macrophage cell line, the preference for cationic particles fell to $20 \%$ over the neutral emulsions and $60 \%$ over the anionic emulsions (Fig. 6D). In addition, the overall uptake of nanoemulsions in RAW cells was about four-fold greater than A375 cells. Macrophage uptake appears to be particularly nanomaterial dependent as contrasting trends are apparent in the literature..$^{\mathbf{8 0 , 1 1 5 , 1 1 8 , 1 2 2 , 1 2 3}}$ Our results, which demonstrate a slight preference for cationic emulsions, have been observed for other soft materials. ${ }^{\mathbf{8 0 , 1 1 4 , 1 2 4}}$ Also of interest is the comparison of unmodified POx emulsions to Pluronic F-68 nanoemulsions (Fig. 6C and D, gray vs. black). The zeta potential (Fig. S21†), and size of these samples are similar, yet POx-stabilized emulsions display lower uptake than Pluronic F68-stabilized emulsions in both cell lines. These results suggest that the poly(2-methyl-2-oxazoline) surface coverage reduces the non-specific uptake of the emulsions as compared to poly(ethylene oxide). Low levels of non-specific uptake are essential for the active-targeting of nanoparticles. ${ }^{125-127}$ Thus, POx-stabilized emulsions are poised to be versatile materials for targeted delivery.

Finally, we corroborated our quantitative flow cytometry data with microscopy and analyzed the cellular localization of the modified droplets. Previous works have shown that cationic and neutral PFC nanoemulsions undergo endocytosis in both macrophage and non-macrophage cells, ${ }^{99,128}$ while other work has found emulsions to fuse with the cell membrane. ${ }^{129}$ To explore the cellular fate of the POx-stabilized emulsions, we performed colocalization studies with LysoTracker on A375 and RAW cells (Fig. 6E and F). Colocalization between rhodamine and LysoTracker fluorescence suggests that the nanoemulsions 
A.

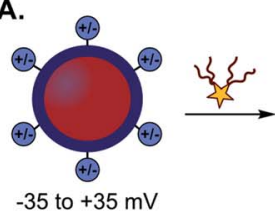

C.

C. Cell Uptake: Non-macrophage (A375)

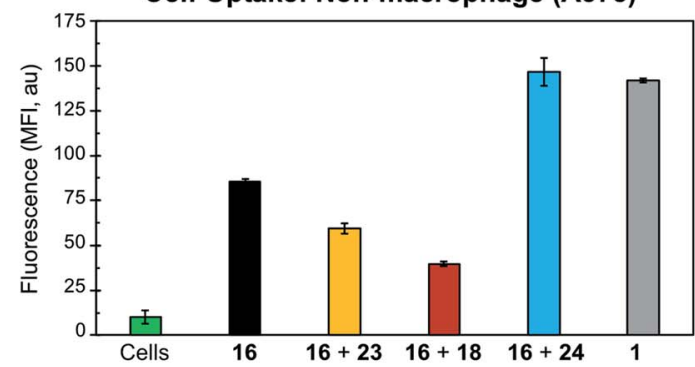

E.
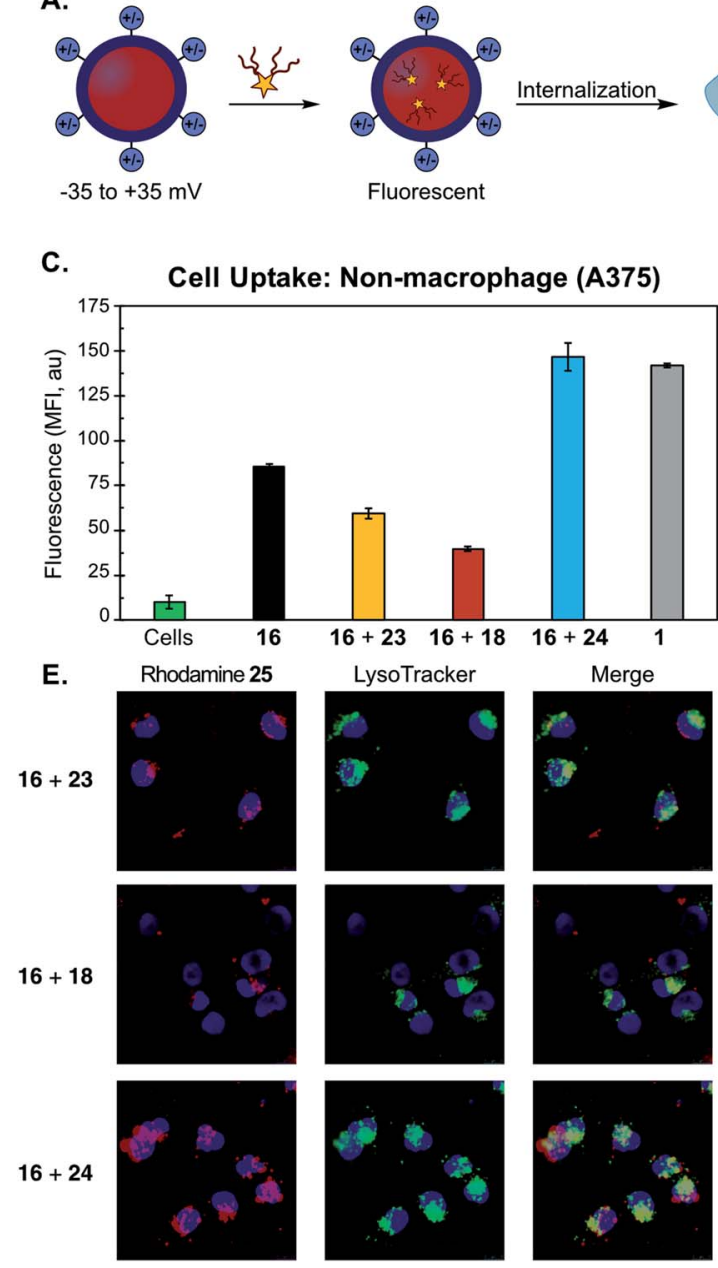

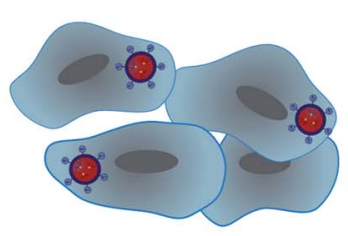

D.
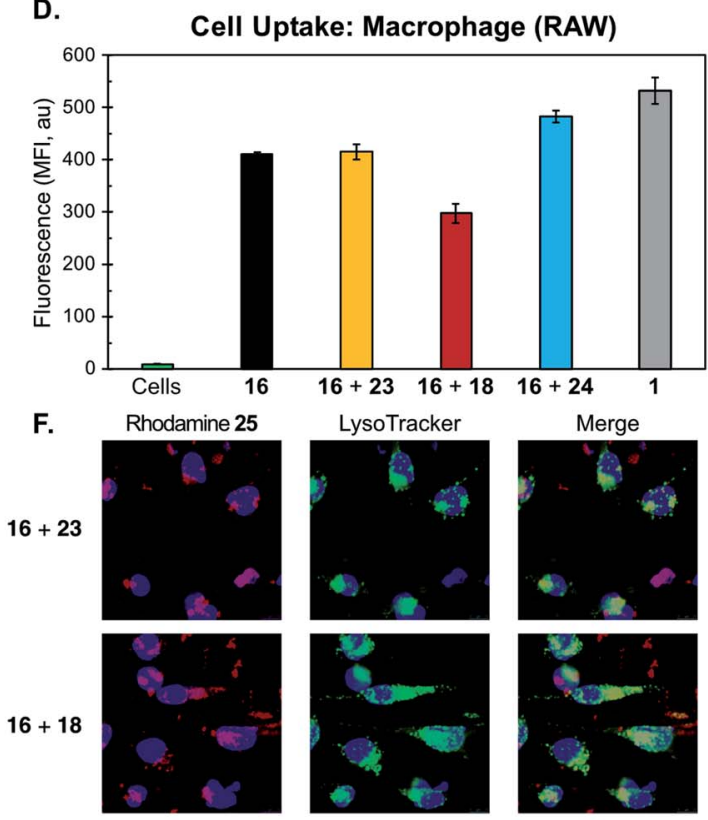

B.

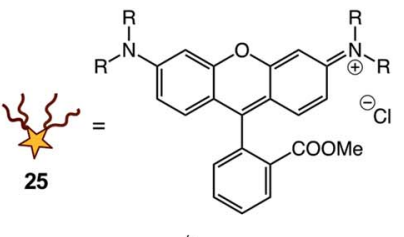

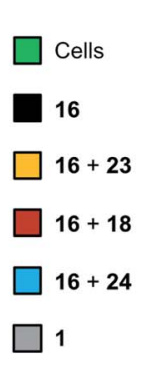

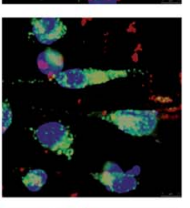

$16+24$
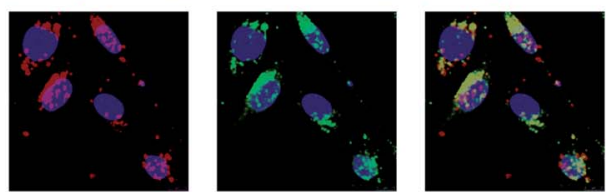

Fig. 6 (A) Schematic of cellular uptake study of differentially charged nanoemulsions. Nanoemulsions were fluorescently labeled via the addition of a fluorous-tagged rhodamine. (B) Fluorous rhodamine 25. (C/D) Flow cytometry of (C) non-macrophage (A375) and (D) macrophage (RAW) cell lines incubated with PFC nanoemulsions. PFC nanoemulsions with modified surface charges were prepared via the thiol-ene modification of emulsions formed from 16 as described in Fig. $4 \mathrm{E}$ and $\mathrm{F}$. Excess reagents were removed via thrice centrifugation and resuspension in $\mathrm{MilliQ} \mathrm{H}_{2} \mathrm{O}$. After the final wash, the emulsions were resuspended in PBS and 25 in acetone was added. The emulsions were rocked for 1 min then introduced to A375 or RAW cells for 3 hours. The cells were thrice washed with excess FACS buffer (PBS plus 1\% FBS) to remove non-uptaken emulsions, lifted with trypsin and transferred to a V-bottom plate. The cells were further washed via centrifugation $(\times 3$, FACS buffer) and analyzed by flow cytometry. Cells were gated (see Fig. S30 and S31 ) and FL2 mean fluorescence intensity (MFI) was plotted. Error bars represent the standard deviation of three replicate samples. Green = control cells; black = emulsions stabilized by 16; yellow = emulsions stabilized by 16 and modified by 23; red = emulsions stabilized by 16 and modified by 18; blue = emulsions stabilized by 16 and modified by 24; grey=emulsions stabilized by 1. (E/F) Confocal microscopy of (E) A375 cells and (F) RAW cells. The procedure was identical to (C/D) except for a one-hour incubation followed by five initial washes ( $3 \times$ media, $2 \times$ FACS buffer). After the final wash, the cells were transferred to an FBS-treated microscope slide, incubated for $1 \mathrm{~h}$ in media, stained with Hoescht dye and LysoTracker Green and imaged via confocal microscopy. These cells were analyzed for rhodamine (Ex $532 \mathrm{~nm}$, false color red) and LysoTracker Green (Ex $488 \mathrm{~nm}$, false color green), and Hoescht dye (Ex $405 \mathrm{~nm}$, false color blue). Scale bar indicates $10 \mu \mathrm{m}$. Images are representative of two independent experiments. See Fig. S32 and S33† for single channel images and DIC.

are internalized via endocytosis. Notably, we also observed an interaction with the cell-surface for the cationic particles, likely due to electrostatic interactions with the anionic membrane. ${ }^{\mathbf{1 1 8}}$ Endocytosis was further supported by analyzing cellular uptake of nanoemulsions at $4{ }^{\circ} \mathrm{C}$, a method of non-specifically inhibiting energy-dependent pathways. ${ }^{130}$ We found that uptake in A375 cells was significantly reduced for all POx-stabilized emulsions $(>45 \%$, Fig. S37†). These results highlight that surface chemistry affects levels of cellular uptake, but does not change the route of internalization. ${ }^{92,118}$
We then assayed the viability of A375 and RAW cells treated with the different POx emulsions as well as a Pluronic F-68 control over a 12 hour incubation period at a surfactant concentration of $7.0 \mathrm{mg} \mathrm{mL}^{-1}$ (Fig. S34-S36†). The anionic POx emulsions did not display any statistically significant toxicity in either cell line. Conversely, cationic emulsions displayed significant macrophage toxicity $(58 \% \pm 1.4 \%$ viability) and less pronounced, though significant, loss of viability in A375 cells ( $87 \% \pm 2.3 \%$ viability). Interestingly, the unfunctionalized POx stabilized PFC nanoemulsions resulted in substantially larger viability loss in RAW cells than the emulsions that underwent 
surface modification with neutral thiol $23(61 \% \pm 0.6 \%$ and $79 \% \pm 3.9 \%$ viability, respectively). Collectively, our results demonstrate that a post-emulsion functionalization approach is essential for tuning the cellular uptake and viability of these diverse, yet underdeveloped, soft nanomaterials.

\section{Conclusions}

We demonstrate the use of amphiphilic poly(2-oxazoline)s to stabilize perfluorocarbon-in-water and oil-in-water nanoemulsions. The living nature of the polymerization allows for the controlled addition of functionalizable comonomers into the hydrophilic block of the polymers to facilitate covalent emulsion functionalization. Through incorporation of these functional handles, the ability to attach azide-modified dyes and neutral or charged thiols to the surface of the droplets was achieved. We prepared a set of equal-size yet differentially charged nanoemulsions, which were employed to explore the dependence of cellular uptake on zeta potential in both macrophage and non-macrophage cell lines. We found that cationic emulsions were preferentially uptaken in both cell types. Overall levels of uptake were lower with poly(2-oxazoline) amphiphiles than poloxamers, making the surfactants and emulsions reported herein promising scaffolds for biomedical applications. The use of this surfactant platform to enable controlled delivery in response to biologically relevant stimuli is ongoing. Additionally, the ability to modify the surface of nanoemulsions should extend these materials to areas of nanotechnology where control over chemical and physical properties is a prerequisite.

\section{Conflicts of interest}

There are no conflicts to declare.

\section{Acknowledgements}

Funding was provided by UCLA, NSF MRI (CHE-1048804), and NIH (training grant to D. A. E., 5T32GM067555-12). We thank the Spokoyny, Maynard, and Deming groups for the use of equipment.

\section{References}

1 Z. Nie, A. Petukhova and E. Kumacheva, Nat. Nanotechnol., 2010, 5, 15-25.

2 S. Park, J.-H. Lim, S.-W. Chung and C. A. Mirkin, Science, 2004, 303, 348-351.

3 K. Liu, Z. Nie, N. Zhao, W. Li, M. Rubinstein and E. Kumacheva, Science, 2010, 329, 197-200.

4 M. Cargnello, A. C. Johnston-Peck, B. T. Diroll, E. Wong, B. Datta, D. Damodhar, V. V. T. Doan-Nguyen, A. A. Herzing, C. R. Kagan and C. B. Murray, Nature, 2015, 524, 450-453.

5 D. Peer, J. M. Karp, S. Hong, O. C. Farokhzad, R. Margalit and R. Langer, Nat. Nanotechnol., 2007, 2, 751-760.
6 E. Caló and V. V. Khutoryanskiy, Eur. Polym. J., 2015, 65, 252-267.

7 C. De Las Heras Alarcón, S. Pennadam and C. Alexander, Chem. Soc. Rev., 2005, 34, 276-285.

8 F. Caruso, T. Hyeon and V. M. Rotello, Chem. Soc. Rev., 2012, 41, 2537-2538.

9 N. A. Liechty, W. B. Kryscio, D. R. Slaughter and B. V. Peppas, Annu. Rev. Chem. Biomol. Eng., 2010, 1, 149173.

10 M. L. Immordino, F. Dosio and L. Cattel, Int. J. Nanomed., 2006, 1, 297-315.

11 M. M. Fryd and T. G. Mason, Annu. Rev. Phys. Chem., 2012, 63, 493-518.

12 F. Sainsbury, B. Zeng and A. P. Middelberg, Curr. Opin. Chem. Eng., 2014, 4, 11-17.

13 H. H. Tayeb, S. Piantavigna, C. B. Howard, A. Nouwens, S. M. Mahler, A. P. J. Middelberg, L. He, S. A. Holt and F. Sainsbury, Soft Matter, 2017, 13, 7953-7961.

14 V. Patravale, P. Dandekar and R. Jain, in Nanoparticulate Drug Delivery, 2012, pp. 1-28.

15 K. O. Aboalnaja, S. Yaghmoor, T. A. Kumosani and D. J. McClements, Expert Opin. Drug Delivery, 2016, 13, 1327-1336.

16 D. J. McClements, in Nanoemulsions, 2018, pp. 3-20.

17 J. Bibette, F. Leal Calderon and P. Poulin, Rep. Prog. Phys., 1999, 62, 969-1033.

18 P. Shah, D. Bhalodia and P. Shelat, Syst. Rev. Pharm., 2010, 1, 24.

19 T. F. Tadros, Applied Surfactants: Principles and Applications, 2005.

20 O. Sonneville-Aubrun, J. T. Simonnet and F. L'Alloret, Adv. Colloid Interface Sci., 2004, 108-109, 145-149.

21 K. P. Velikov and E. Pelan, Soft Matter, 2008, 4, 1964-1980.

22 D. J. McClements, Soft Matter, 2011, 7, 2297-2316.

23 A. Fahr and X. Liu, Expert Opin. Drug Delivery, 2007, 4, 403416.

24 M. J. Lawrence and G. D. Rees, Adv. Drug Delivery Rev., 2000, 45, 89-121.

25 A. Spernath and A. Aserin, Adv. Colloid Interface Sci., 2006, 128-130, 47-64.

26 C. S. Chern, Prog. Polym. Sci., 2006, 31, 443-486.

27 A. Imhof and D. J. Pine, Nature, 1997, 389, 948-951.

28 N. Anton, J. P. Benoit and P. Saulnier, J. Controlled Release, 2008, 128, 185-199.

29 K. Min, H. Gao and K. Matyjaszewski, J. Am. Chem. Soc., 2006, 128, 10521-10526.

30 B. Y. Guan, L. Yu and X. W. Lou, J. Am. Chem. Soc., 2016, 138, 11306-11311.

31 A. Musyanovych, V. Mailänder and K. Landfester, Biomacromolecules, 2005, 6, 1824-1828.

32 W. Zhang and Q. Zhong, J. Agric. Food Chem., 2009, 57, 9181-9189.

33 H. Yang, L. Fu, L. Wei, J. Liang and B. P. Binks, J. Am. Chem. Soc., 2015, 137, 1362-1371.

34 K. Manabe, X. M. Sun and S. Kobayashi, J. Am. Chem. Soc., 2001, 123, 10101-10102. 
35 M. F. Attia, S. M. Dieng, M. Collot, A. S. Klymchenko, C. Bouillot, C. A. Serra, M. Schmutz, M. Er-Rafik, T. F. Vandamme and N. Anton, Macromol. Biosci., 2017, 17, 1-13.

36 T. F. Tadros, in Emulsion Formation and Stability, 2013, pp. 1-75.

37 A. M. Fernandez and L. Jebbanema, Paint Coat. Ind., 2007, 23, 62-68.

38 L. Bai and D. McClements, Processes, 2016, 4, 1-18.

39 D. J. McClements, Curr. Opin. Colloid Interface Sci., 2012, 17, 235-245.

40 T. G. Mason, J. N. Wilking, K. Meleson, C. B. Chang and S. M. Graves, J. Phys.: Condens. Matter, 2006, 18, R635-R666.

41 J. K. Hensel, A. P. Carpenter, R. K. Ciszewski, B. K. Schabes, C. T. Kittredge, F. G. Moore and G. L. Richmond, Proc. Natl. Acad. Sci. U. S. A., 2017, 114, 13351-13356.

42 A. F. Dexter, A. S. Malcolm and A. P. J. Middelberg, Nat. Mater., 2006, 5, 502-506.

43 J. A. Hanson, C. B. Chang, S. M. Graves, Z. Li, T. G. Mason and T. J. Deming, Nature, 2008, 455, 85-88.

44 S. H. Medina, M. S. Michie, S. E. Miller, M. J. Schnermann and J. P. Schneider, Angew. Chem., Int. Ed., 2017, 56, 1140411408.

45 Y. Huang, A. M. Vezeridis, J. Wang, Z. Wang, M. Thompson, R. F. Mattrey and N. C. Gianneschi, J. Am. Chem. Soc., 2017, 139, 15-18.

46 Z. Yang, J. Wei, Y. I. Sobolev and B. A. Grzybowski, Nature, 2018, 553, 313-318.

47 L. D. Zarzar, V. Sresht, E. M. Sletten, J. A. Kalow, D. Blankschtein and T. M. Swager, Nature, 2015, 518, 520-524.

48 P. Brown, C. P. Butts and J. Eastoe, Soft Matter, 2013, 9, 2365-2374.

49 A. Gianella, A. J. Mieszawska, F. J. M. Hoeben, H. M. Janssen, P. A. Jarzyna, D. P. Cormode, K. D. Costa, S. Rao, O. C. Farokhzad, R. Langer, Z. A. Fayad and W. J. M. Mulder, Chem. Commun., 2013, 49, 9392-9394.

50 G. Praveen Kumar and A. Divya, Med. Chem., 2015, 5, 272-284.

51 K. Akazawa, F. Sugihara, T. Nakamura, H. Matsushita, H. Mukai, R. Akimoto, M. Minoshima, S. Mizukami and K. Kikuchi, Angew. Chem., Int. Ed., 2018, 57, 16742-16747.

52 D. J. McClements and S. M. Jafari, Adv. Colloid Interface Sci., 2018, 251, 55-79.

53 K. Ziani, Y. Chang, L. McLandsborough and D. J. McClements, J. Agric. Food Chem., 2011, 59, 6247-6255.

54 D. Guzey and D. J. McClements, Adv. Colloid Interface Sci., 2006, 128-130, 227-248.

55 A. H. Saberi, B. Zeeb, J. Weiss and D. J. McClements, J. Colloid Interface Sci., 2015, 455, 172-178.

56 T. Tokle, U. Lesmes and D. J. McClements, J. Agric. Food Chem., 2010, 58, 9825-9832.

57 H. F. Wang, D. Wibowo, Z. Shao, A. P. J. Middelberg and C. X. Zhao, Langmuir, 2017, 33, 7957-7967.

58 B. J. Zeng, Y. P. Chuan, B. O'Sullivan, I. Caminschi, M. H. Lahoud, R. Thomas and A. P. J. Middelberg, Small, 2013, 9, 3736-3742.

59 C. Chaix, E. Pacard, A. Elaïssari, J. F. Hilaire and C. Pichot, Colloids Surf., B, 2003, 29, 39-52.
60 M. Li, W. Jiang, Z. Chen, S. Suryaprakash, S. Lv, Z. Tang, X. Chen and K. W. Leong, Lab Chip, 2017, 17, 635-639.

61 S. Ursuegui, M. Mosser and A. Wagner, RSC Adv., 2016, 6, 94942-94948.

62 L. Tang, X. Yang, Q. Yin, K. Cai, H. Wang, I. Chaudhury, C. Yao, Q. Zhou, M. Kwon, J. A. Hartman, I. T. Dobrucki, L. W. Dobrucki, L. B. Borst, S. Lezmi, W. G. Helferich, A. L. Ferguson, T. M. Fan and J. Cheng, Proc. Natl. Acad. Sci. U. S. A., 2014, 111, 15344-15349.

63 E. Dickinson, Pure Appl. Chem., 1992, 64, 1721-1724.

64 T. Tadros, J. Cosmet. Sci., 2006, 57, 153-169.

65 M. Lunn and T. Fausnight, Pediatrics, 2011, 128, 1025-1028.

66 B. C. You, A. S. Jang, J. S. Han, H. W. Cheon, J. S. Park, J. H. Lee, S. W. Park, D. J. Kim and C. S. Park, Allergy, Asthma Immunol. Res., 2012, 4, 46-48.

67 C. A. Peng and Y. C. Hsu, Artif. Cells, Blood Substitutes, Immobilization Biotechnol., 2001, 29, 483-492.

68 C. Farace, P. Sánchez-Moreno, M. Orecchioni, R. Manetti, F. Sgarrella, Y. Asara, J. M. Peula-García, J. A. Marchal, R. Madeddu and L. G. Delogu, Sci. Rep., 2016, 6, 1-14.

69 R. P. Garay, R. El-Gewely, J. K. Armstrong, G. Garratty and P. Richette, Expert Opin. Drug Delivery, 2012, 9, 1319-1323. 70 T. X. Viegas, M. D. Bentley, J. M. Harris, Z. Fang, K. Yoon, B. Dizman, R. Weimer, A. Mero, G. Pasut and F. M. Veronese, Bioconjugate Chem., 2011, 22, 976-986.

71 B. Pidhatika, M. Rodenstein, Y. Chen, E. Rakhmatullina, A. Mühlebach, C. Acikgöz, M. Textor and R. Konradi, Biointerphases, 2012, 7, 1-15.

72 O. Koshkina, D. Westmeier, T. Lang, C. Bantz, A. Hahlbrock, C. Würth, U. Resch-Genger, U. Braun, R. Thiermann, C. Weise, M. Eravci, B. Mohr, H. Schlaad, R. H. Stauber, D. Docter, A. Bertin and M. Maskos, Macromol. Biosci., 2016, 16, 1287-1300.

73 K. Knop, R. Hoogenboom, D. Fischer and U. S. Schubert, Angew. Chem., Int. Ed., 2010, 49, 6288-6308.

74 K. Lava, B. Verbraeken and R. Hoogenboom, Eur. Polym. J., 2015, 65, 98-111.

75 A. Gupta, H. B. Eral, T. A. Hatton and P. S. Doyle, Soft Matter, 2016, 12, 2826-2841.

76 J. Mosquera, M. Henriksen-Lacey, I. García, M. MartínezCalvo, J. Rodríguez, J. L. Mascareñas and L. M. LizMarzán, J. Am. Chem. Soc., 2018, 140, 4469-4472.

77 P. P. Pillai, S. Huda, B. Kowalczyk and B. A. Grzybowski, J. Am. Chem. Soc., 2013, 135, 6392-6395.

78 S. G. Elci, Y. Jiang, B. Yan, S. T. Kim, K. Saha, D. F. Moyano, G. Yesilbag Tonga, L. C. Jackson, V. M. Rotello and R. W. Vachet, ACS Nano, 2016, 10, 5536-5542.

79 Y. Bai, H. Xing, P. Wu, X. Feng, K. Hwang, J. M. Lee, X. Y. Phang, Y. Lu and S. C. Zimmerman, ACS Nano, 2015, 9, 10227-10236.

80 L. Adamiak, M. A. Touve, C. L. M. Leguyader and N. C. Gianneschi, ACS Nano, 2017, 11, 9877-9888.

81 L. I. Kaberov, B. Verbraeken, A. Riabtseva, J. Brus, Y. Talmon, P. Stepanek, R. Hoogenboom and S. K. Filippov, ACS Macro Lett., 2018, 7, 7-10. 
82 L. I. Kaberov, B. Verbraeken, A. Riabtseva, J. Brus, A. Radulescu, Y. Talmon, P. Stepanek, R. Hoogenboom and S. K. Filippov, Macromolecules, 2018, 51, 6047-6056.

83 R. Ivanova, T. Komenda, T. B. Bonné, K. Lüdtke, K. Mortensen, P. K. Pranzas, R. Jordan and C. M. Papadakis, Macromol. Chem. Phys., 2008, 209, 2248-2258.

84 R. Hoogenboom, F. Wiesbrock, H. Huang, M. A. M. Leenen, H. M. L. Thijs, S. F. G. M. Van Nispen, M. Van Der Loop, C. A. Fustin, A. M. Jonas, J. F. Gohy and U. S. Schubert, Macromolecules, 2006, 39, 4719-4725.

85 T. B. Bonné, K. Lüdtke, R. Jordan and C. M. Papadakis, Macromol. Chem. Phys., 2007, 208, 1402-1408.

86 R. H. Jin, J. Mater. Chem., 2004, 14, 320-327.

87 F. Wiesbrock, R. Hoogenboom, M. Leenen, S. F. G. M. Van Nispen, M. Van Der Loop, C. H. Abeln, A. M. J. Van Den Berg and U. S. Schubert, Macromolecules, 2005, 38, 7957-7966.

88 B. D. Monnery, V. V. Jerca, O. Sedlacek, B. Verbraeken, R. Cavill and R. Hoogenboom, Angew. Chem., Int. Ed., 2018, 57, 15400-15404.

89 T. G. Mason, J. N. Wilking, K. Meleson, C. B. Chang and S. M. Graves, J. Phys.: Condens. Matter, 2006, 18, R635-R666. 90 E. M. Sletten and T. M. Swager, Chem. Sci., 2016, 7, 5091-5097. 91 E. M. Sletten and T. M. Swager, J. Am. Chem. Soc., 2014, 136, 13574-13577.

92 R. A. Day, D. A. Estabrook, J. K. Logan and E. M. Sletten, Chem. Commun., 2017, 53, 13043-13046.

93 M. A. Miller and E. M. Sletten, Org. Lett., 2018, 20, 6850-6854.

94 J. A. Gladysz, D. P. Curran and I. T. Horváth, Handbook of Fluorous Chemistry, 2005.

95 R. K. Spence, E. D. Norcross, J. Costabile, S. McCoy, A. C. Cernaianu, J. B. Alexander, M. J. Pello, U. Atabek and R. C. Camishion, Artif. Cells, Blood Substitutes, Immobilization Biotechnol., 1994, 22, 955-963.

96 T. Mitsuno, H. Ohyanagi and R. Naito, Ann. Surg., 1982, 195, 60-69.

97 R. L. Goodman, R. E. Moore, M. E. Davis, D. Stokes and J. M. Yuhas, Int. J. Radiat. Oncol., Biol., Phys., 1984, 10, 1421-1424.

98 J. G. Riess, Artif. Cells, Blood Substitutes, Immobilization Biotechnol., 1994, 22, 215-234.

99 J. M. Janjic, M. Srinivas, D. K. K. Kadayakkara and E. T. Ahrens, J. Am. Chem. Soc., 2008, 130, 2832-2841.

100 M. M. Kaneda, S. Caruthers, G. M. Lanza and S. A. Wickline, Ann. Biomed. Eng., 2009, 37, 1922-1933.

101 R. Díaz-López, N. Tsapis and E. Fattal, Pharm. Res., 2010, 27, 1-16.

102 Y. Cheng, H. Cheng, C. Jiang, X. Qiu, K. Wang, W. Huan, A. Yuan, J. Wu and Y. Hu, Nat. Commun., 2015, 6, 1-8.

103 M. J. Patrick, J. M. Janjic, H. Teng, M. R. O'Hear, C. W. Brown, J. A. Stokum, B. F. Schmidt, E. T. Ahrens and A. S. Waggoner, J. Am. Chem. Soc., 2013, 135, 18445-18457.

104 H. C. Kolb, M. G. Finn and K. B. Sharpless, Angew. Chem., Int. Ed., 2001, 40, 2004-2021.

105 C. E. Hoyle and C. N. Bowman, Angew. Chem., Int. Ed., 2010, 49, 1540-1573.

106 R. Luxenhofer and R. Jordan, Macromolecules, 2006, 39, 3509-3516.
107 A. Gress, A. Völkel and H. Schlaad, Macromolecules, 2007, 40, 7928-7933.

108 K. Kempe, R. Hoogenboom, M. Jaeger and U. S. Schubert, Macromolecules, 2011, 44, 6424-6432.

109 T. He, D. Jańczewski, S. Jana, A. Parthiban, S. Guo, X. Zhu, S. S. C. Lee, F. J. Parra-Velandia, S. L. M. Teo and G. J. Vancso, J. Polym. Sci., Part A: Polym. Chem., 2016, 54, 275-283.

110 B. Pelaz, P. Del Pino, P. Maffre, R. Hartmann, M. Gallego, S. Rivera-Fernández, J. M. De La Fuente, G. U. Nienhaus and W. J. Parak, ACS Nano, 2015, 9, 6996-7008.

111 Y. Jiang, S. Huo, T. Mizuhara, R. Das, Y. W. Lee, S. Hou, D. F. Moyano, B. Duncan, X. J. Liang and V. M. Rotello, ACS Nano, 2015, 9, 9986-9993.

112 L. W. C. Ho, W. Y. Yung, K. H. S. Sy, H. Y. Li, C. K. K. Choi, K. C. F. Leung, T. W. Y. Lee and C. H. J. Choi, ACS Nano, 2017, 11, 6085-6101.

113 J. Wang, W. Mao, L. L. Lock, J. Tang, M. Sui, W. Sun, H. Cui, D. Xu and Y. Shen, ACS Nano, 2015, 9, 7195-7206.

114 K. Xiao, Y. Li, J. Luo, J. S. Lee, W. Xiao, A. M. Gonik, R. G. Agarwal and K. S. Lam, Biomaterials, 2011, 32, 34353446.

115 S. S. Yu, C. M. Lau, S. N. Thomas, W. Gray Jerome, D. J. Maron, J. H. Dickerson, J. A. Hubbell and T. D. Giorgio, Int. J. Nanomed., 2012, 7, 799-813.

116 S. Krasnici, A. Werner, M. E. Eichhorn, M. Schmitt-Sody, S. A. Pahernik, B. Sauer, B. Schulze, M. Teifel, U. Michaelis, K. Naujoks and M. Dellian, Int. J. Cancer, 2003, 105, 561-567.

117 C. Kelly, C. Jefferies and S.-A. Cryan, J. Drug Delivery, 2011, 2011, 1-11.

118 E. Fröhlich, Int. J. Nanomed., 2012, 7, 5577-5591.

119 A. Verma and F. Stellacci, Small, 2010, 6, 12-21.

120 F. Zhao, Y. Zhao, Y. Liu, X. Chang, C. Chen and Y. Zhao, Small, 2011, 7, 1322-1337.

121 F. Alexis, E. Pridgen, L. K. Molnar and O. C. Farokhzad, Mol. Pharmaceutics, 2008, 5, 505-515.

122 C. D. Walkey, J. B. Olsen, H. Guo, A. Emili and W. C. W. Chan, J. Am. Chem. Soc., 2012, 134, 2139-2147.

123 H. H. Gustafson, D. Holt-Casper, D. W. Grainger and H. Ghandehari, Nano Today, 2015, 10, 487-510.

124 C. R. Miller, B. Bondurant, S. D. McLean, K. A. McGovern and D. F. O'Brien, Biochemistry, 1998, 37, 12875-12883.

125 E. Blanco, H. Shen and M. Ferrari, Nat. Biotechnol., 2015, 33, 941-951.

126 B. Wang, C. V. Galliford and P. S. Low, Nanomedicine, 2014, 9, 313-330.

127 Y. H. Bae and K. Park, J. Controlled Release, 2011, 153, 198205.

128 C. Grapentin, F. Mayenfels, S. Barnert, R. Süss, R. Schubert, S. Temme, C. Jacoby, J. Schrader and U. Flögel, Nanomedicine, 2014, 268-286.

129 M. M. Kaneda, Y. Sasaki, G. M. Lanza, J. Milbrandt and S. A. Wickline, Biomaterials, 2010, 31, 3079-3086.

130 S. Vranic, N. Boggetto, V. Contremoulins, S. Mornet, N. Reinhardt, F. Marano, A. Baeza-Squiban and S. Boland, Part. Fibre Toxicol., 2013, 10, 1-16. 